\title{
Psicología de la educación virtual. Aprender y enseñar con las tecnologías de la información y la comunicación.
}

\author{
Por: César Coll y Carlos Monereo (Eds.) (2008). \\ Madrid: Morata Ediciones.
}

Edilberto Lasso Cárdenas ${ }^{1}$

Universidad Nacional Abierta y a Distancia (UNAD), Colombia

edilberto.lasso@unad.edu.co

1 Magíster en educación. Actualmente es tutor e investigador, del grupo UBUNTU, de la Escuela Ciencias de la Educación (ECEDU) de la Universidad Nacional Abierta y a Distancia 
César Coll y Carles Monereo, editores del libro Psicología de la educación virtual, son dos psicólogos de la educación, al ocuparse del impacto de la educación con las tecnologías de la información y la comunicación, incitan el interés de profesionales de otras disciplinas para que se involucren dialógicamente alrededor de estos asuntos, que datan desde los inicios del siglo XXI. Profesionales de la tecnología, la pedagogía, la epistemología, la antropología y la didáctica no pueden pasar inadvertidas las investigaciones, preocupaciones, consideraciones, juicios y propuestas que estos psicólogos educativos promueven en este libro, es apremiante que las disciplinas estén en condiciones de mezclarse, enredarse, conectarse e imbricarse unas a otras, como oferentes y deudoras de reflexión, en torno a las construcciones epistemológicas, el impacto de las TIC en la educación, los entornos virtuales, los alcances en el aprendizaje en red, y las competencias que se requieren en los mundos virtuales.

Los autores de este libro, conciben que el mundo de las tecnologías incide notoriamente en las dinámicas sociales y en las nuevas proyecciones educativas. En cuanto a la primera, destacan el influjo de la tecnología en la sociedad (denominada también como comunidad virtual, nueva polis, infópolis o una nueva sociedad-red). Respecto a la segunda, lo educativo estos estudiosos se apartan de una concepción según la cual,que la escuela se resiste a los nuevos retos sociales, educativos y tecnológicos; evita, además evita, toda confrontación yo colisión epistemológica que logre desestabilizarlala desestabilice en sus cimientos o apuestas formativas. Esta escuela correría el riesgo de eclipsarse y sucumbir al interior de un cerrado refugio, o caverna como otros algunos la podrían tildarla,tildan al mejor estilo platónico,. Finalmente, la escuela teme ponerse en entredicho, por lo que se podría asistir previsiblemente al desvanecimiento o hundimiento de aquello que la define como tal.

La escuela no puede seguir pretendiendo enclaustrar el aprendizaje en los muros, pues estaría asintiendo el divorcio entre la escuela y la sociedad, lo que se traduciría en las culpas ajenas de las propias responsabilidades. Entonces, es posible que la escuela cuestione a una sociedad a le que pertenecen los individuos que entran en sus aulas y la sociedad, a su turno, acusaría a la escuela de lanzar a los egresados a la vida laboral, sin las competencias exigidas para tal fin.

Los autores del libro se inclinan por una "escuela nómada" en la educación virtual. La cual implica, por parte de los actores del proceso educativo, ir cerrando la brecha socio-cognitiva. También reclama asumir, por parte del navegante de la tecnología y la educación, una nueva terminología, en asocio con el espíritu de apertura a nuevas formas de entender e incorporar críticamente al aprendizaje, aquellos componentes de la tecnología: la realidad virtual (el ciberespacio o el espacio virtual), la comunicación por redes, los nuevos tipos de temporalidades. Estos componentes se manifiestan en las nuevas comprensiones de perfil de estudiante y tutor. Todo esto implica, construir una nueva arquitectura básica de un 
entorno inteligente de aprendizaje que favorecerá procesos de autorregulación de los procesos cognitivos, no desvinculados de las multitudes interconectadas.

Los actores educativos que entienden, indagan, articulan y establecen conexiones entre las TIC en la educación, evitarán caer en reduccionismos que conllevan un fracaso en el aprendizaje, en el sentido que, mientras algunos lanzarían diatribas en contra de las herramientas tecnológicas, otros harían lo mismo contra una apuesta pedagógica determinada. Otros, que también se atienen a la percepción dual de las TIC y la educación, procuran defender sin el soporte investigativo, su interdependencia, por lo que terminan forzando una concepción equivocada acerca de que a las herramientas tecnológicas les compete suplir los vacíos educativos, o que un enfoque pedagógico está obligado a resolver una deficiencia respecto a la tecnología.

Ahora bien, la incorporación de las TIC a la educación no transforma ni mejora automáticamente los procesos educativos, insisten los investigadores, per se no es garantía inmediata de la resolución de los problemas educativos imperantes. De hecho, es posible encontrar aulas virtuales con soportes de herramientas tecnológicas, que parchean las propuestas educativas con unos cursos y contenidos, pero que, replican los mismos errores de ciertos sectores de educación presencial o tradicional.

Ahora, algunas modalidades virtuales pueden convertir los cursos en cápsulas, a los que ciertos estudiantes van a adentrase con lentes tradicionales (pues los criterios que los rigen, por lo general, son tradicionales, a los que han sido acostumbrados en su educación básica y media) o con espíritu nómada (nativos digitales), puede ser factible que hagan de cada curso su morada, pues encuentran todo a su disposición con tan sólo dar un clic, de modo que ahí se queda complacido y pasivo. Algunos cursos, estudiantes y tutores pueden estar moviéndose en un monodiscurso respecto a la enseñanza y el aprendizaje, en este sentido la tecnología podría ser vista como una simple herramienta eléctrica o trasto al que se acude esporádicamente. Los que así piensan, considerarían, que la tecnología no tiene incidencia alguna en la transformación de los procesos sociales o educativos, y al contrario, los que se apartan de esa mirada estrictamente instrumentalista de la tecnología y hasta de la misma educación, consideran que el curso virtual es un pretexto para potenciar en los tutores y estudiantes la búsqueda de ventanas emergentes o de establecer conexiones, redes de aprendizaje o sociales con diversas visiones de mundo y cultura. Esta es una apuesta para que los estudiantes entrecrucen sus apuesta cognitivas y sociales con las más diversas narratopedias que están interactuando en el ciberespacio, o como se infiere de lo que observan los autores del libro, los tutores y estudiantes, en su condición de cyborgs, deben combinar y distribuir sus funciones híbridas técnico cognitivas y sus e-identidades.

La incorporación de las TIC en la educación no es para hacer lo mismo que se venía haciendo sin ellas, ni para utilizarlas como un "plan b", en donde se desestima 
o minimiza el sentido y exigencias de la educación virtual, y a las que se acude solo como "tabla de salvación" frente a las ocupaciones laborales cotidianas, las cuales requieren la primacía en dedicación y tiempos. La tecnología puede entonces aparecer como un simple "cacharrería", objeto extraño o distante del yo. Tampoco se utiliza para crear un útero cibernético con el ánimo de aislarse intencionadamente de los demás, de esta forma los cursos virtuales se transforman en unos espacios para "colgar" los trabajos personales y nada más.

En cuanto a lo que promueven Monereo y Castells, es necesario que tutores y estudiantes tengan que recablear las mentes, en el momento de acercarse reflexivamente en este nuevo paradigma que vincula tecnología y educación. Es posible que de esa forma se empezará a vislumbrar un primer atisbo de lo que podría representar el impacto de las TIC en la educación y en la sociedad.

La incidencia e impacto de las TIC en la educación y en la sociedad influirá, como lo abordan Coll y Monereo, en las buenas prácticas educativas, en el diseño de aprendizajes en entornos virtuales, la utilidad de los medios (soportados por intencionalidades explícitas o implícitas), los diseños producidos por el tutor (tutores autoproductores) y que responden a las necesidades de los estudiantes (más que acudir únicas fuentes externas y que responden, en no pocas ocasiones, a otros intereses educativos). Con esta gama de interpretaciones se favorecerá, en la educación virtual, la flexibilidad, la apertura, la democratización, el espíritu de indagación personal, la creación de redes alrededor de intereses educativos y sociales.

Queda entonces pendiente el imperioso reto de seguir fomentando las investigaciones que marquen otros derroteros acerca de las nuevas comprensiones de las antropologías que emergen con las TIC, o que subyacen a la hora de vincular las TIC con la educación, pues el estudiante que aprende es un actor social que se está re-escribiendo y re-definiendo a partir de este giro copernicano en el que las TIC, además de repercutir en otras formas de aprender, están permeando la carne. Cuerpo y tecnología, dirán otros investigadores, son mutuamente extensiones y prolongaciones.

Los autores en ocasiones enfatizan la importancia de las competencias en el uso de herramientas, pero es posible que estos manejos no sean suficientes, se requiere por parte del interesado, incorporar críticamente en sus interlocuciones, una nueva terminología, que refleja una nuevo ethos tecnológico: realidad virtual, ciberespacio, redes de aprendizaje, nuevos roles de tutor y estudiante. Posiblemente, los nuevos contactos y las nuevas comunicaciones proferidas por los nativos digitales no solamente las están estableciendo con la pantalla, es factible que por su espíritu curioso, imaginativo y nómada se estén atreviendo, sin mordazas y sin intermediarios, a atravesarlas... ahora están transitando, revestidos de nuevas presencias fluidas, por inmensas memorias en línea. 